\title{
Contents and Changes of Potassium in Plough Layers of Xuancheng, South Anhui Province
}

\author{
Ka Lin 1,2, Decheng Li ${ }^{*}$, Xiaodong Song1, Chaolong Zu³, Chaoqiang Jiang3, Jia Shen, \\ Chengxin $\mathrm{Ma}^{4}$, Qin Gao4, Qifa Zhu ${ }^{4}$, Xuejun $\mathrm{Ji}^{4}$, Guo Zhang ${ }^{4}$, Lin Xue
}

${ }^{1}$ State Key Laboratory of Soil and Sustainable Agriculture, Institute of Soil Science, Chinese Academy of Sciences, Nanjing, China

${ }^{2}$ University of the Chinese Academy of Sciences, Beijing, China

${ }^{3}$ Institute of Tobacco Science, Anhui Agricultural Academy of Sciences, Hefei, China

${ }^{4}$ Wannan Tobacco Co. Ltd., Xuancheng, China

Email: *klin@issas.ac.cn, dcli@issas.ac.cn

How to cite this paper: Lin, K., Li, D.C., Song, X.D., Zu, C.L., Jiang, C.Q., Shen, J., Ma, C.X., Gao, Q., Zhu, Q.F., Ji, X.J., Zhang, G. and Xue, L. (2017) Contents and Changes of Potassium in Plough Layers of Xuancheng, South Anhui Province. Agricultural Sciences, 8, 348-355. https://doi.org/10.4236/as.2017.85026

Received: February 26, 2017

Accepted: May 16, 2017

Published: May 22, 2017

Copyright $\odot 2017$ by authors and Scientific Research Publishing Inc. This work is licensed under the Creative Commons Attribution International License (CC BY 4.0).

http://creativecommons.org/licenses/by/4.0/

\section{cc) (i) Open Access}

\begin{abstract}
Xuancheng City is the dominant tobacco-planting area of Anhui province due to the high quality of the tobacco leaves. However, the potassium content in the tobacco leaves shows a gradual decreasing trend in recent years, which may be attributed partly to the possible low potassium content in topsoil of tobacco-planting farmland. Therefore, the content data in the year of 20052007 of rapidly available potassium (RA-K) of 7730 topsoil samples mainly under double rice rotation or wheat/rice-rice rotation at that time and the content data of slowly available potassium (SA-K) and RA-K of 124 typical topsoil samples in the year of 2015 under tobacco-rice rotation were used and compared in order to disclose the status of topsoil potassium and to provide a guidance for reasonable potassium fertilization in Xuancheng. The results showed that in 2005-2007 RA-K content ranged from $1 \mathrm{mg} \cdot \mathrm{kg}^{-1}$ to 844 $\mathrm{mg} \cdot \mathrm{kg}^{-1}$ with an average of $68 \mathrm{mg} \cdot \mathrm{kg}^{-1}$, and $82.7 \%$ of topsoil samples were insufficient in RA-K $\left(<100 \mathrm{mg} \cdot \mathrm{kg}^{-1}\right)$. Comparatively in $2015 \mathrm{SA}-\mathrm{K}$ content ranged from $230 \mathrm{mg} \cdot \mathrm{kg}^{-1}$ to $1340 \mathrm{mg} \cdot \mathrm{kg}^{-1}$ with an average of $595 \mathrm{mg} \cdot \mathrm{kg}^{-1}$, and $13.7 \%$ of soil samples were insufficient in SA-K $\left(<400 \mathrm{mg} \cdot \mathrm{kg}^{-1}\right)$; RA-K content ranged from $46 \mathrm{mg} \cdot \mathrm{kg}^{-1}$ to $352 \mathrm{mg} \cdot \mathrm{kg}^{-1}$ with an average of $134 \mathrm{mg} \cdot \mathrm{kg}^{-1}$, and $25.8 \%$ of soil samples were insufficient in RA-K $\left(<100 \mathrm{mg} \cdot \mathrm{kg}^{-1}\right)$. The above data show that RA-K content has increased gradually in farmland topsoil mainly due to fertilization since 1980s, particularly to farmland under tobacco-rice rotation, but insufficient RA-K in topsoil is still widely and serious for farmland under double rice rotation or wheat/rice-rice rotation. Under tobacco-rice rotation, RA-K insufficiency usually occurred in the farmlands which plant tobacco less than 3 years, indicating more potassium fertilizer should be applied.
\end{abstract}




\section{Keywords}

Rapidly Available Potassium (RA-K), Slowly Available Potassium (SA-K), Topsoil, Tobacco-Rice Rotation, Xuancheng City

\section{Introduction}

The potassium content is an important index to evaluate the quality of fluecured tobacco [1] [2]. Generally speaking, the potassium content in tobacco leaves with high quality should not be less than $2 \%$ [3]. The potassium content in tobacco leaves of the United States, Zimbabwe and Brazil and other countries ranges from $4 \%$ to $6 \%$ while it is only ranges from $1.5 \%$ to $2.0 \%$ in China, except for the Yunnan-Guizhou Plateau of southwest China and Sanming of Fujian province of southeast China [4] [5]. Thus, promoting the potassium content in tobacco leaves has been one of the key studies in China.

Xuancheng City $\left(29^{\circ} 57^{\prime} \mathrm{N}-31^{\circ} 19^{\prime} \mathrm{N}, 117^{\circ} 58^{\prime} \mathrm{E}-119^{\circ} 40^{\prime} \mathrm{E}\right)$, located in south Anhui Province, has been the dominant tobacco-planting region of this province since tobacco was initially planted in 2007 due to its well-known "burnt-sweet smelling" style [6] [7]. The tobacco-planting area is nearly $10,000 \mathrm{hm}^{2}$ with 10,000 tons of tobacco leaf yield [6]-[11]. However, according to the annual monitoring data, the average potassium content in tobacco leaves of Xuancheng City shows a decreasing trend, it alarmingly decreased from $2 \%$ in 2007 [6] to $1.5 \%$ in 2014

The potassium in tobacco leaves mainly comes from soil and applied potassium fertilizer [12], and the rational potassium fertilization depends upon the background of soil potassium content [13]. Therefore, in this paper, we analyzed the potassium contents in the topsoil in 2005-2007 and in 2015 of Xuancheng City, disclosed the changes and mechanism of potassium status in order to instruct the reasonable potassium fertilization for producing tobacco leaves with high content of potassium.

\section{Methods and Materials}

\subsection{The Sources of Soil Potassium Data}

The contents of potassium in topsoil were from the following sources in this paper, one is the contents of rapidly available potassium (RA-K) of 7730 topsoil samples $(0-20 \mathrm{~cm})$ in 2005-2007 obtained from the programme of Soil Testing and Formula Fertilization (STFF), and the other is the contents of slowly available potassium (SA-K) and RA-K of 124 topsoil samples collected in 2015 from the farmlands of model tobacco-farmers.

The spatial distribution of topsoil samples in the two periods are shown in Figure 1 and Table 1 . The contents of SA-K and RA-K were determined by the method of flame photometer after topsoil samples were digested by $\mathrm{HNO}_{3}$ and extracted by acetamide for the content measurements of SA-K and RA-K, re 


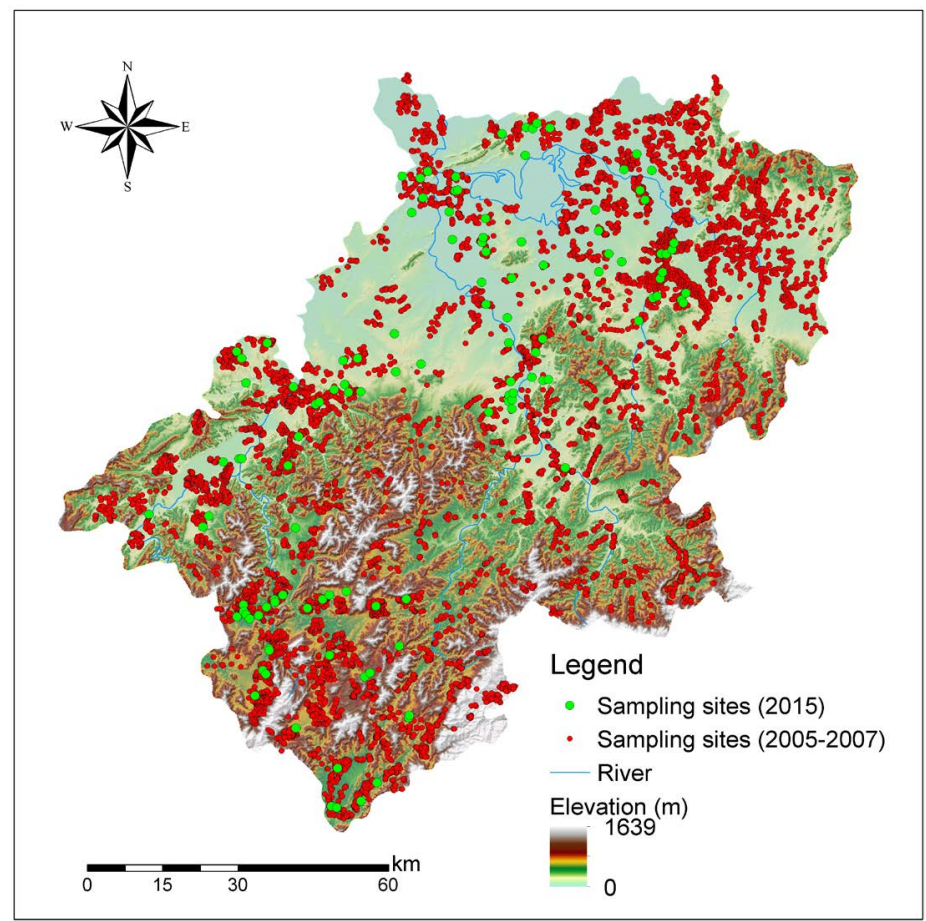

Figure 1. Spatial distribution of topsoil samples in Xuancheng City, South Anhui Province (7730 samples in 2005-2007, 124 samples in 2015).

Table 1. Regional distribution of topsoil samples in Xuancheng City.

\begin{tabular}{ccccccccc}
\hline Region & $\begin{array}{c}\text { Xuanzhou } \\
(\mathrm{XZ})\end{array}$ & $\begin{array}{c}\text { Langxi } \\
(\mathrm{LX})\end{array}$ & $\begin{array}{c}\text { Guangde } \\
(\mathrm{GD})\end{array}$ & $\begin{array}{c}\text { Ningguo } \\
(\mathrm{NG})\end{array}$ & $\begin{array}{c}\text { Jingxian } \\
(\mathrm{JX})\end{array}$ & $\begin{array}{c}\text { Jixi } \\
(\mathrm{JXX})\end{array}$ & $\begin{array}{c}\text { Jingde } \\
(\mathrm{JD})\end{array}$ & Total \\
\hline $2005-2007$ & 923 & 1083 & 1308 & 930 & 1425 & 1073 & 988 & 7730 \\
2015 & 42 & 11 & 13 & 8 & 19 & 10 & 21 & 124 \\
\hline
\end{tabular}

spectively [14].

\subsection{The Grading Standards of Soil Potassium Contents}

Table 2 is the grading standards of SA-K and RA-K used in this study, which is simplified on the basis of grades of potassium contents adopted in the $2^{\text {nd }} \mathrm{Na}$ tional Soil Survey

(http://wenku.baidu.com/view/3f7f297e27284b73f242505c.html).

\subsection{Methods of Data Statistics and Mapping}

Data were analyzed with Microsoft Excel 2013 and IBM Statistics SPSS 20.0, the spatial distribution of topsoil samples was mapped on the platform of Esri ArcGIS 10.3.

\section{Results}

\subsection{Rapidly Available Potassium Contents of Topsoil in 2005-2007}

Table 3 shows the statistic information of RA-K contents of topsoil samples in 
Table 2. Content grades of slowly available potassium and rapidly available potassium used in this study.

\begin{tabular}{ccccc}
\hline Index & Sufficient & Medium & Deficient & Severe deficient \\
\hline SA-K $\left(\mathrm{mg} \cdot \mathrm{kg}^{-1}\right)$ & $>500$ & $500-400$ & $400-300$ & $<300$ \\
RA-K $\left(\mathrm{mg} \cdot \mathrm{kg}^{-1}\right)$ & $>150$ & $150-100$ & $100-50$ & $<50$ \\
\hline
\end{tabular}

Table 3. Statistics of rapidly available potassium contents in topsoil samples in 2005-2007, Xuancheng City.

\begin{tabular}{cccccccccc}
\hline \multicolumn{2}{c}{ Region } & XZ & LX & GD & NG & JX & JXX & JD & Total \\
\hline $\begin{array}{c}\text { RA-K } \\
\left(\mathrm{mg} \cdot \mathrm{kg}^{-1}\right)\end{array}$ & Range & $1-826$ & $9-420$ & $6-310$ & $15-470$ & $2-611$ & $11-844$ & $8-371$ & $1-844$ \\
& Average & 57 & 71 & 68 & 94 & 66 & 77 & 47 & 68 \\
\hline
\end{tabular}

2005-2007. To the whole Xuancheng City, RA-K content ranged from $1 \mathrm{mg} \cdot \mathrm{kg}^{-1}$ to $844 \mathrm{mg} \cdot \mathrm{kg}^{-1}$ with an average of $68 \mathrm{mg} \cdot \mathrm{kg}^{-1}$, while the average RA-K contents in different administrative regions ranged from $47 \mathrm{mg} \cdot \mathrm{kg}^{-1}$ to $94 \mathrm{mg} \cdot \mathrm{kg}^{-1}$, generally in the deficient grade.

Table 4 shows the sample number distribution in different grades of RA-K contents in 2005-2007. To the whole Xuancheng City, 82.7\% (6392 samples) of the total samples were in the deficient grade while $5.8 \%$ ( 9 samples) of the total samples were in sufficient grade, which indicate generally RA-K content of topsoil samples are insufficient. To various administrative regions, the deficiency of RA-K contents were most serious in Jingde and Xuanzhou, more than $90 \%$ of the corresponding total samples were in the deficient grade, followed by GuangDe, LangXi and Jixi, about $80 \%-90 \%$ of the corresponding total samples were in the deficient grade, while $60 \%-80 \%$ of the corresponding total samples in Jingxian and Ningguo were in the deficient grade.

\subsection{Potassium Contents of Topsoil Samples in 2015}

Table 5 shows the statistic information of the contents of SA-K and RA-K in topsoil samples from the model tobacco-farmers' farmlands of Xuancheng City in 2015.

To the whole region, SA-K content ranged from $230 \mathrm{mg} \cdot \mathrm{kg}^{-1}$ to $1340 \mathrm{mg} \cdot \mathrm{kg}^{-1}$ with an average of $595 \mathrm{mg} \cdot \mathrm{kg}^{-1}$, in the sufficient grade; RA-K content ranged from $46 \mathrm{mg} \cdot \mathrm{kg}^{-1}$ to $352 \mathrm{mg} \cdot \mathrm{kg}^{-1}$ with an average of $134 \mathrm{mg} \cdot \mathrm{kg}^{-1}$, in the medium grade.

To various administrative regions, 1) average SA-K content in Jingxian was $485 \mathrm{mg} \cdot \mathrm{kg}^{-1}$, in the medium grade, average SA-K contents ranged from 545 $\mathrm{mg} \cdot \mathrm{kg}^{-1}$ to $810 \mathrm{mg} \cdot \mathrm{kg}^{-1}$ in other region, in the sufficient grade. 2) average RA-K contents were $151 \mathrm{mg} \cdot \mathrm{kg}^{-1}$ and $185 \mathrm{mg} \cdot \mathrm{kg}^{-1}$ in Guangde and Ningguo, respectively, in the sufficient grade; average RA-K content ranged from $105 \mathrm{mg} \cdot \mathrm{kg}^{-1}$ to $141 \mathrm{mg} \cdot \mathrm{kg}^{-1}$ in other region, in the medium grade.

Table 6 shows the sample number distribution in various grades of SA-K contents of topsoil samples in 2015. To the whole region, 13.7\% (17 samples) of 
Table 4. Statistics of rapidly available potassium contents in different grades in topsoil samples in 2005-2007, Xuancheng City.

\begin{tabular}{|c|c|c|c|c|c|c|c|c|c|c|}
\hline \multirow{2}{*}{ Region } & \multicolumn{2}{|c|}{ Severe deficient } & \multicolumn{2}{|c|}{ Deficient } & \multicolumn{2}{|l|}{ Medium } & \multicolumn{2}{|c|}{ Sufficient } & \multicolumn{2}{|l|}{ Total } \\
\hline & Sample No. & $\%$ & Sample No. & $\%$ & Sample No. & $\%$ & Sample No. & $\%$ & Sample No. & $\%$ \\
\hline $\mathrm{XZ}$ & 450 & 48.7 & 396 & 42.9 & 68 & 7.4 & 9 & 0.9 & 923 & 100 \\
\hline LX & 317 & 29.2 & 593 & 54.8 & 129 & 11.9 & 44 & 4 & 1083 & 100 \\
\hline GD & 409 & 31.2 & 722 & 55.2 & 134 & 10.2 & 43 & 3.3 & 1308 & 100 \\
\hline NG & 98 & 10.5 & 509 & 54.7 & 225 & 24.2 & 98 & 10.6 & 930 & 100 \\
\hline JX & 434 & 30.4 & 641 & 45 & 190 & 13.3 & 160 & 11.3 & 1425 & 100 \\
\hline JXX & 379 & 35.4 & 508 & 47.3 & 106 & 9.9 & 80 & 7.4 & 1073 & 100 \\
\hline $\mathrm{JD}$ & 674 & 68.2 & 262 & 26.5 & 36 & 3.6 & 16 & 1.6 & 988 & 100 \\
\hline Total & 2761 & 35.7 & 3631 & 47 & 888 & 11.5 & 450 & 5.8 & 7730 & 100 \\
\hline
\end{tabular}

Table 5. Statistics of slowly available potassium and rapidly available potassium contents in topsoil samples in 2015, Xuancheng City.

\begin{tabular}{cccccc}
\hline \multirow{2}{*}{ Region } & \multirow{2}{*}{ Sample Number } & \multicolumn{2}{c}{$\mathrm{S} \mathrm{A}-\mathrm{K}\left(\mathrm{mg} \cdot \mathrm{kg}^{-1}\right)$} & \multicolumn{2}{c}{$\mathrm{R} \mathrm{A}-\mathrm{K}\left(\mathrm{mg} \cdot \mathrm{kg}^{-1}\right)$} \\
\cline { 3 - 5 } & 42 & $230-1340$ & 595 & $46-352$ & 134 \\
\hline XZ & 11 & $340-730$ & 545 & $106-200$ & 141 \\
LX & 13 & $390-920$ & 618 & $68-292$ & 151 \\
GD & 8 & $390-800$ & 601 & $106-320$ & 185 \\
NG & 19 & $250-690$ & 485 & $58-224$ & 128 \\
JX & 10 & $230-950$ & 622 & $46-352$ & 136 \\
JXX & 21 & $450-1340$ & 810 & $46-158$ & 105 \\
JD & 124 & $230-1340$ & 595 & $46-352$ & 134 \\
All & & & & & \\
\hline
\end{tabular}

Table 6. Statistics of slowly available potassium contents at various grades in topsoil samples in 2015, Xuancheng City.

\begin{tabular}{|c|c|c|c|c|c|c|c|c|c|c|}
\hline \multirow{2}{*}{ Region - } & \multicolumn{2}{|c|}{ Severe deficient } & \multicolumn{2}{|l|}{ Deficient } & \multicolumn{2}{|l|}{ Medium } & \multicolumn{2}{|c|}{ Sufficient } & \multicolumn{2}{|l|}{ Total } \\
\hline & Sample No. & $\%$ & Sample No. & $\%$ & Sample No. & $\%$ & Sample No. & $\%$ & Sample No. & $\%$ \\
\hline $\mathrm{XZ}$ & 0 & 0 & 7 & 16.7 & 13 & 31.0 & 22 & 52.3 & 42 & 100 \\
\hline LX & 0 & 0 & 2 & 18.2 & 3 & 27.3 & 6 & 54.6 & 11 & 100 \\
\hline GD & 0 & 0 & 1 & 7.7 & 4 & 30.8 & 8 & 61.6 & 13 & 100 \\
\hline NG & 0 & 0 & 1 & 12.5 & 0 & 0 & 7 & 87.5 & 8 & 100 \\
\hline $\mathrm{JX}$ & 1 & 5.3 & 2 & 10.5 & 7 & 36.8 & 9 & 47.4 & 19 & 100 \\
\hline JXX & 3 & 30.0 & 0 & 0 & 0 & 0 & 7 & 70.0 & 10 & 100 \\
\hline JD & 0 & 0 & 0 & 0 & 2 & 9.5 & 19 & 90.5 & 21 & 100 \\
\hline Total & 4 & 3.2 & 13 & 10.5 & 29 & 23.4 & 78 & 62.9 & 124 & 100 \\
\hline
\end{tabular}

the total samples were in the deficient grade while $62.9 \%$ (78 samples) of the total samples were in sufficient grade. To various administrative regions, SA-K content in Jingde was in the sufficient grade, while $8 \%-30 \%$ of the corresponding total samples in other regions were in the deficient grade. 
Table 7 shows the sample number distribution in various grades of RA-K contents of topsoil samples in 2015. To the whole region, 25.8\% (32 samples) of the total samples were in the deficient grade, while $29.8 \%$ (37 samples) of the total samples were in the sufficient grade. To various administrative regions, RA-K content in Langxi and Ningguo were in the sufficient grade, while $15-36 \%$ of the corresponding total samples in other regions were insufficient in RA-K.

\section{Discussion}

According to the data of RA-K contents in 1987 obtained during the $2^{\text {nd }}$ National Soil Survey in Xuancheng City, $89.4 \%$ of topsoils were lack of RA-K $(<100$ $\left.\mathrm{mg} \cdot \mathrm{kg}^{-1}\right)$, however, in 2005-2007 the percentage of RA-K deficient was decreased down to $82.7 \%$, indicating RA-K status of farmlands were slightly improved, which is attributed to potassium fertilization: before 2005-2007, most of the farmlands in Xuancheng were given priority to double rice rotation or ricewheat rotation. Historical field survey data showed that during this period the annual average crop yield (double rice or rice + wheat) was $1000 \mathrm{~kg} / 667 \mathrm{~m}^{2}$ in total, the grains usually contain $0.4 \%$ of $\mathrm{K}_{2} \mathrm{O}$, almost all the crop straws were returned to the fields or burnt directly in the fields [15] [16], thus about $4 \mathrm{~kg} / 667$ $\mathrm{m}^{2}$ of $\mathrm{K}_{2} \mathrm{O}$ was removed out from the topsoil by the harvested grains. Meanwhile, average $80 \mathrm{~kg} / 667 \mathrm{~m}^{2}$ of the compound fertilizer (containing $8 \%$ of $\mathrm{K}_{2} \mathrm{O}$ ) was applied annually to the fields, about $6.4 \mathrm{~kg} / 667 \mathrm{~m}^{2}$ of $\mathrm{K}_{2} \mathrm{O}$ brought into the topsoils, so annually the "net" input of $\mathrm{K}_{2} \mathrm{O}$ to the topsoils is about $2.4 \mathrm{~kg} / 667 \mathrm{~m}^{2}$.

For the surveyed model farmers' farmlands with tobacco-rice rotation, only $25.8 \%$ of the total 124 topsoil samples are insufficient in RA-K content, while the proportion of RA-K content in medium or above grades was $74.2 \%$ in total, indicating that obvious improved in RA-K content in topsoil under the tobacco-rice rotation compared with the data under double rice cropping or rice-wheat rotation in 2005-2007, which is resulted from surplus potassium fertilizers applied into the topsoils during the tobacco-planting period. The field survey data surveyed in 2015 showed that during the tobacco-planting period, 55

Table 7. Statistics of rapidly available potassium contents at various grades in topsoil samples in 2015, Xuancheng City.

\begin{tabular}{ccccccccccc}
\hline \multirow{2}{*}{ Region } & \multicolumn{2}{c}{ Severe deficient } & \multicolumn{2}{c}{ Deficient } & \multicolumn{2}{c}{ Medium } & \multicolumn{2}{c}{ Sufficient } & \multicolumn{3}{c}{ Total } \\
\cline { 2 - 10 } & Sample No. & $\%$ & Sample No. & $\%$ & Sample No. & $\%$ & Sample No. & $\%$ & Sample No. & $\%$ \\
\hline XZ & 0 & 0 & 15 & 35.7 & 15 & 35.7 & 12 & 28.6 & 42 & 100 \\
LX & 0 & 0 & 0 & 0 & 7 & 63.6 & 4 & 36.4 & 11 & 100 \\
GD & 0 & 0 & 2 & 15.4 & 4 & 30.8 & 7 & 53.9 & 13 & 100 \\
NG & 0 & 0 & 0 & 0 & 3 & 37.5 & 5 & 62.5 & 8 & 100 \\
JX & 0 & 0 & 5 & 26.3 & 9 & 47.4 & 5 & 26.3 & 19 & 100 \\
JXX & 1 & 10.0 & 3 & 30.0 & 3 & 30.0 & 3 & 30.0 & 10 & 100 \\
JD & 2 & 9.5 & 4 & 19.0 & 14 & 66.7 & 1 & 4.8 & 21 & 100 \\
Total & 3 & 2.4 & 29 & 23.4 & 55 & 44.4 & 37 & 29.8 & 124 & 100 \\
\hline
\end{tabular}


$\mathrm{kg} / 667 \mathrm{~m}^{2}$ of tobacco specific fertilizer (containing $24 \%$ of $\mathrm{K}_{2} \mathrm{O}$ ), $5 \mathrm{~kg} / 667 \mathrm{~m}^{2}$ of potassium sulphate (containing $50 \%$ of $\mathrm{K}_{2} \mathrm{O}$ ) and $6.6 \mathrm{~kg} / 667 \mathrm{~m}^{2}$ of potassium nitrate (containing $44 \%$ of $\mathrm{K}_{2} \mathrm{O}$ ) were applied into the topsoil, while during the rice-planting period $15 \mathrm{~kg} / 667 \mathrm{~m}^{2}$ of rice specific fertilizer (containing $15 \%$ of $\mathrm{K}_{2} \mathrm{O}$ ) was applied to the soil, thus $20.85 \mathrm{~kg} / 667 \mathrm{~m}^{2}$ of $\mathrm{K}_{2} \mathrm{O}$ in total was input into the topsoil from fertilization. Both the yields of tobacco leaves and stems are about $150 \mathrm{~kg} / 667 \mathrm{~m}^{2}$, which contain $2.2 \%$ and $2.0 \%$ of $\mathrm{K}_{2} \mathrm{O}$, respectively, but the tobacco stems usually were removed out from the tobacco fields to avoid disease spread. The yield of late rice is about $500 \mathrm{~kg} / 667 \mathrm{~m}^{2}$, which containing $0.4 \%$ of $\mathrm{K}_{2} \mathrm{O}$, also almost all the rice straws were returned to the fields or burnt directly in the fields, thus, about $5.0 \mathrm{~kg}$ of $\mathrm{K}_{2} \mathrm{O}$ was removed out from the soil by the leaves and stems of tobacco and the grains of rice, so the "net" input of $\mathrm{K}_{2} \mathrm{O}$ into the topsoil is about $15.85 \mathrm{~kg} / 667 \mathrm{~m}^{2}$ annually. It is the reason for mean RA-K content (134 mg. $\left.\mathrm{kg}^{-1}\right)$ in the model tobacco-farmers' farmlands in 2015 is $49.3 \%$ higher than that under double rice rotation or rice-wheat rotation in 2005-2007 $\left(68 \mathrm{mg} \cdot \mathrm{kg}^{-1}\right)$, also higher than that of the 20 long-term monitoring farmlands (under double rice rotation or rice-wheat rotation) in Xuancheng City in the same year (ranged from $58 \mathrm{mg} \cdot \mathrm{kg}^{-1}$ to $188 \mathrm{mg} \cdot \mathrm{kg}^{-1}$ with an average of 104 $\left.\mathrm{mg} \cdot \mathrm{kg}^{-1}\right)$.

Some tobacco-farmers thought that no potassium fertilizers should be applied into fields during the rice planting period, but the field survey data surveyed in 2015 showed further that for the $87.5 \%$ of 'new tobacco-planting farmlands' (under tobacco-rice rotation less than 3 years, 23 topsoil samples in total in 2015), the potassium accumulative effect in topsoils is not obvious, RA-K content in topsoil is still in the deficient grade, so the fields need continuous potassium fertilization during the rice planting period.

\section{Conclusion}

Generally, the content of rapidly available potassium content has increased gradually in topsoil farmlands in Xuancheng City, which is mainly due to potassium fertilization since 1980s, particularly due to farmlands under tobacco-rice rotation which initially started since 2007 . However, more potassium fertilizers should be applied into the farmlands under double rice rotation or wheat-rice rotation, while more potassium fertilizers should be used during the rice planting period to the farmlands under tobacco-rice rotation less than 3 years.

\section{Acknowledgements}

This study was supported by the Program of Anhui Branch of China National Tobacco Co. (20150551009), the External Operation Program of BIC, Chinese Academy of Sciences (151432KYSB2015007), and the Intergovernmental Special Program of National Key R\&D Plan (2016YFE0112700) and Sino-EU Cooperation Programme iSQAPER. We also thank the supports and help from the Soil and Fertilization Station of Xuancheng in STFF data supply and field sampling activity. 


\section{References}

[1] Gething, P.A. (1993) Potassium Fertilization Technology of Main Crops. Beijing Agricultural University Press, Beijing.

[2] Hu, D.J., Dong, C.R. and Ge, D.Z. (1993) Theory and Practice of Plant Potassium Nutrition. Hunan Science and Technology Press, Changsha.

[3] Marchand, M., Etourneaud, F. and Bourrie, B. (1997) The Effect of Different Varieties of Potash Fertilizer on Tobacco Yield and Chemical Composition. Chinese Tobacco Science, 2, 6-11. http://www.cnki.com.cn/Article/CJFDTotal-ZGYV702.001.htm

[4] Hu, G.S., Zhao, Y.K., Cao, Z.H., Zhao, X., Zhao, Z.S., Chen, J.H., Zhang, X., Zhou, X.R. and Li, Z.L. (1997) The Evaluation of The Chemical Elements and Some Organic Components in Flue-Cured Leaf Tobacco from The Main Tobacco Production Provinces of China. Acta Tabacaria Sinica, 3, 36-43. http://www.cnki.com.cn/Article/CJFDTotal-ZGYB199701005.htm

[5] Wang, Y.T., Xie, J.P. and Li, Z.H. (2010) Tobacco Planting Regionalization of China. Science Press, Beijing.

[6] Zu, C.L., Ji, X.J., Ma, C.X., Yang, C., Liu, G.S. and Qiu, L.Y. (2010) Relationship Between Mineral Elements in Flue-Cured Tobacco Leaves, Cultivated Soils and Burnt-Sweet Smelling Formation in South Anhui. Soils, 42, 26-32. http://www.cnki.com.cn/Article/CJFDTOTAL-TURA201001006.htm

[7] Wannan Tobacco Co. Ltd. (2010) Exploration and Practice of Modern Tobacco Agriculture. Hefei University of Technology Press, Hefei.

[8] Xi, J.F., Li, X.S., Wang, D.Z., Ji, X.J., Shen, S.D., Yang, P., Zhou, L.X. and Li, D.C. (2009) On Soil Suitability for Burnt-Sweet Smelling Distinctive Tobacco Growth in Xuancheng. Soils, 41, 1018-1020. http://www.cnki.com.cn/Article/CJFDTotal-TURA200906030.htm

[9] Ji, X.J., Wang, D.Z., Shen, S.D., Xi, J.F., Li, D.C., Li, X.S., Yang, P. and Zhou, L.X. (2010) Quantitative Evaluation on Suitable Potential for Distinctive Tobacco Growth in Xuancheng. Soils, 42, 648-651. http://www.cnki.com.cn/Article/CJFDTotal-TURA201004026.htm

[10] Zhang, G., Ji, X.J., Li, D.C., Wang, D.Z., Shen, S.D. and Xiang, Z.H. (2012) On Quantitative Evaluation and Spatial Distribution of Major Properties for Tobacco Soil in Xuancheng City of Anhui Province. Soils, 44, 873-879. http://www.cnki.com.cn/Article/CJFDTotal-TURA201205026.htm

[11] Ji, X.J., Shen, S.D., Xue, L., Zhang, G., Zhuang, Y., Wu, X.J., Li, D.C. and Zu, C.L. (2013) Soil Taxonomy of Typical Tobacco Fields in Xuancheng of Southern Anhui. Soils, 45, 763-765. http://www.cnki.com.cn/Article/CJFDTotal-TURA201304032.htm

[12] Institute of Tobacco Research of CASS (2005) Tobacco Cultivation of China. Shanghai Science and Technology Press, Shanghai.

[13] Lu, J.L. (2003) Plant Nutrition. 2nd Edition, China Agricultural University Press, Beijing.

[14] Zhang, G.L. and Gong, Z.T. (2012) Soil Survey Laboratory Methods. Science Press, Beijing.

[15] Yang, Y.R., Wang, X.X., Zhan, T.L. and Li, D.C. (2014) Utilization of Crop Straw Resources in Anhui Province, Eastern China. Bulgarian Journal of Agricultural Science, 20, 1302-1310. http://www.doc88.com/p-0949785000216.html

[16] Huang, C.Y. (2000) Pedology. China Agriculture Press, Beijing. 
Submit or recommend next manuscript to SCIRP and we will provide best service for you:

Accepting pre-submission inquiries through Email, Facebook, LinkedIn, Twitter, etc. A wide selection of journals (inclusive of 9 subjects, more than 200 journals)

Providing 24-hour high-quality service

User-friendly online submission system

Fair and swift peer-review system

Efficient typesetting and proofreading procedure

Display of the result of downloads and visits, as well as the number of cited articles Maximum dissemination of your research work

Submit your manuscript at: http://papersubmission.scirp.org/

Or contact as@scirp.org 